\title{
Almas dobles: Fronteras que se diluyen en Las aventuras de la China Iron de Gabriela Cabezón Cámara
}

Guillermo Portela ${ }^{1}$

\section{RESUMEN}

La dicotomía civilización/barbarie, desde Sarmiento orientadora del proceso de construcción nacional, se sirvió de las fronteras como una de las piezas fundantes en la construcción de identidades nacionales subalternas y excluidas. Esto produjo grupos que habitualmente fueron invisibilizados o, cuando no, denostados por la literatura nacional subsidiaria del discurso de poder. Tomando las categorías de frontera y reescritura (Garramuño, 1997), en este artículo intentaremos visualizar el proceso deconstructivo que lleva a cabo la novela de Gabriela Cabezón Cámara, Las aventuras de la China Iron (2017) para permeabilizar, erosionar y derribar esas líneas geográficas e imaginarias y muchas veces arbitrarias que llamamos fronteras. Partimos de la hipótesis de que este ejercicio de reescritura, en el solo hecho de abatir los límites geográficos habilita, a su vez, la desarticulación de todas las convenciones sociales que operan como segregadores jerárquicos de la alteridad, por ejemplo, los nombres o las razas, las procedencias sociales o culturales y, más que nada los géneros y las orientaciones sexuales. De esta forma, podemos preguntarnos si la difuminación de la frontera, que blindaba el mundo distópico del indio del de los cristianos en el Martín Fierro, no facilita la entrada a la utopía en la reescritura de Cabezón Cámara.

Palabras claves: frontera; identidad; sexualidad; reescritura; alteridad.

1 Universidad Nacional de San Martín. Mail de contacto: guillermo portela@hotmail.com 


\begin{abstract}
The civilization / barbarism dichotomy, from Sarmiento guiding the national construction process, served as frontiers as one of the founding pieces in the construction of subaltern and excluded national identities. This produced groups that were habitually invisible or, when not, reviled by the national literature subsidiary of the discourse of power. Returning to these categories, frontier and rewriting (Garramuño, 1997), in this article we will try to visualize the deconstructive process carried out by Gabriela Cabezón Cámara's novel, The Adventures of China Iron (2017), to permeabilize, erode and tear down those geographical and imaginary lines and often arbitrary, which we call borders. We start from the hypothesis that this rewriting exercise, in the mere fact of breaking down geographical boundaries, enables, in turn, the dismantling of all social conventions that operate as hierarchical segregators of otherness, for example, names or races, social or cultural backgrounds and, more than anything, gender and sexual orientation. In this way, we can ask ourselves if the blurring of the border, which shielded the dystopian world of the Indian from that of the Christians in Martín Fierro, does not facilitate the entrance to utopia in the rewriting of Cabezón Cámara.
\end{abstract}

Keywords: border; identity; sexuality; rewrite; otherness.

Fecha de recepción: 28/11/2019

Fecha de aceptación: 26/06/2020 


\section{Almas dobles: Fronteras que se diluyen en Las aventuras de la China Iron de Gabriela Cabezón Cámara}

\section{FRONTERAS QUE SE DILUYEN: AQUÍ ME PONGO A ANDAR}

El gaucho Martín Fierro de José Hernández fue publicado en 1872. Esta primera parte culmina con Fierro, el personaje que da nombre al poema hernandiano, y su ladero Cruz perseguidos por la justicia cruzando la frontera hacia las tierras del indio. Siete años después, en 1879, La vuelta de Martín Fierro vio la letra impresa. Este texto comienza con Fierro de retorno en tierras cristianas. El gaucho que supo tener "hijos, hacienda y mujer" (Hernández 1978, p. 27), pero se había desgraciado con la justica, ahora vuelve redimido y menos contestatario de la autoridad. En los versos siguientes contará las desgracias que vivió al otro lado de la frontera: "Besé esta tierra bendita, / Que ya no pisa el salvaje" (Hernández 1978, p. 138) canta con alivio. En su relato no solo estará invisibilizada la voz del indio, sino que también se hará una construcción totalmente negativa de estos pueblos. La Vuelta, como es conocida la segunda parte del poema de Hernández, parece no ser otra cosa que la vuelta del purgatorio, de la otredad que no tiene redención, la vuelta de la nada misma.

Las aventuras de la China Iron llega para llenar los vacíos que dejó el poema de Hernández. Su personaje, una china que hoy catalogaríamos como feminista e indigenista y supo ser la esposa abandonada por Fierro, no se sienta a esperar y avanza por el desierto argentino, penetra la frontera del indio con mucho menos prejuicio que aquel gaucho perseguido.

De este modo, la China Iron se erige, en el comienzo del relato, como una prototípica protagonista de novela de iniciación. Virgen de cualquier conocimiento, en la triste opacidad, esta joven toma registro "de una pobreza que era [...] más falta de ideas que de ninguna otra cosa" (Cabezón Cámara, 2018, p. 11). De tal forma, desde el honesto desparpajo que ignora toda convención social, transgredir para ella parece más fácil. Si, por un lado, Fierro tiene plena conciencia del dejar atrás, del huir, del traspasar límites, por otro lado, esta china no es perseguida sino, más bien, perseguidora y, para ella, el concepto de frontera como aquella raya o, mejor dicho, zona que separa a la humanidad en dos categorías, los de adentro y los de afuera, los nacionales y los extranjeros, nosotros y ellos, carece de toda relevancia. Así, desaprensiva y con la asequibilidad que brinda la monotonía de la llanura pampeana que desdibuja todos los bordes, la china no es capaz de advertir su tránsito: "No sentía que dejaba nada atrás, apenas el polvo que levantaba la carreta" (Cabezón Cámara, 2018, p. 18). Este pequeño gran acto de dejar el rancho atrás, de romper la quietud que se podría esperar de un personaje femenino, viuda o abandonada, es la primera gran barrera derruida y es, asimismo, el impulso que sacudirá todas las demás.

La presencia de mujeres, y especialmente las chinas, como personajes/protagonistas en la literatura nacional constituyeron una ausencia, salvo escasas y olvidadas excepciones entre las que podemos citar a La mujer de Martín Fierro de Severo Manso (1916) o Lucía Miranda de Rosa Guerra (1860). Esto no debería parecer raro si tenemos en cuenta que, como señala Diana Marre (2003), la construcción de identidades nacionales tuvo su principal anclaje en la construcción de identidades de género 
(heterosexuales y masculinas), étnicas y territoriales, pues entonces, deberíamos poner especial énfasis en el rol trascendental que jugaron las élites criollas en su esfuerzo por articular discursos nacionales con intenciones de constituir imaginarios culturales de identidad.

Es precisamente bajo esta concepción del discurso que la indagación sobre los procesos de construcción identitaria de la nacionalidad "puede articularse como lectura crítica de la/s identidad/es en su lucha por instaurar realidades en orden a las matrices e ideologemas que guiaron la configuración y reproducción de los proyectos hegemónicos de la nacionalidad construida y por construir" (Moyano, 2008, p. 6). En contraposición al discurso dominante y mayoritariamente falocéntrico, la novela de Cabezón Cámara parte del relevante supuesto que trata de dar lugar a la necesaria reflexión sobre la dimensión performativa del lenguaje y su poder instaurativo de nuevas realidades, marco desde el cual reconocemos que, aunque muchas veces, "el lenguaje parece rendirse ante el poder de la materialidad de lo real, y lo que manda no es la flexible liviandad de las palabras, sino el frío estupor de las cosas", otras tantas veces "el lenguaje se nos presenta como materia fundante y definitiva de lo real" (Moyano, 2008, p. 6). No obstante, no es un rasgo lingüístico el que le proporciona poder performativo a un enunciado, ni tampoco un rasgo material del mismo, sino "una dimensión que le permite al enunciado no solo producir un efecto desde la acción que construye, sino también y sobre todo instaurar una realidad que, antes de su ejecución, era virtualmente inexistente" (Aguilar, 2004, p. 4). Por esta particularidad del lenguaje, la performatividad llega a ser gestante del sujeto, su identidad, sus creencias $y$, si estos grupos son dominantes u ostentan el poder de legitimar, terminan, a su vez, por formar identidades nacionales.

Ahora bien, desde el comienzo de la novela la china brega por su identidad, su nombre: "Llamar, no me llamaba: nací huérfana, ¿es eso posible?" (Cabezón Cámara, 2018, p. 12). En otras palabras, en esta lucha, el personaje de Cabezón Cámara afrontará la configuración y preservación de su propia identidad, tanto en el ámbito personal como el social. Este último es mucho más conflictivo, ya que supone la instauración de una legalidad que le es exógena. Es decir, requiere fundar un "yo" que sea, a su vez, legitimado y visibilizado por el "otro". Esto origina reacciones sociales que se orientan muchas veces al rechazo. Como señala Aguilar, esto se debe a que la performatividad edifica "una legalidad que es control, ley y vía de inconmensurabilidad desde la imposición sobre el cuerpo del otro de un modo de ver y experimentar el mundo" (2004, p. 7). No hay relaciones sociales sin lucha por la identidad. Es así que, la china, al verse viuda de Fierro, logra por fin reconocimiento, "hasta el capataz me dio su pésame en esos días, los últimos de mi vida como china" (Cabezón Cámara, 2018, p. 14).

Una vez lanzada al desierto se resuelve el problema del nombre. La primera frontera nítida que la pampa ofrece dio la oportunidad del acto performativo de dejar atrás el pasado de nomen nescio. "Apenas nos cruzamos con un río con orilla, paró la gringa los bueyes" (Cabezón Cámara, 2018, p. 21). Cuando Liz, la gringa, le preguntó el nombre, "La China” contestó. "La China” (ya no como sinónimo de hembra del gaucho sino con mayúsculas) nace de nuevo en el punto muerto que la había dejado olvidada el poema de Hernández: "la nada" (Viola, 2017). Finalmente, el nombre, "China Josephine Star Iron" fue el pretencioso resultado de esa tarde de bautismo y, será también, el campo fértil para que subyaga la representación de distintos sujetos 
sociales subalternos. "China" con mayúscula derriba el muro que vela ese sector (las chinas) de mujeres rioplatenses. A este respecto, Marre (2003) asegura que una de las principales explicaciones sobre el silencio respecto de las mujeres de las pampas, debe buscarse en una larga tradición que considera a la pampa como habitada exclusivamente por hombres solos. Otro caso distinto ocurre con "Josephine", este apelativo, empleado a lo largo de la novela en su diminutivo, "Jose", personaliza lo masculino del personaje permeabilizando las fronteras del género: "yo misma puedo ser mujer y puedo ser varón" (Cabezón Cámara, 2018, p. 181). Lo mismo sucede con el nombre del cachorro, un perro macho que bautiza "Estreya", y del gaucho Rosario que llaman "Rosa", ambos feminizados. En otro orden de ideas, "Star Iron", el apellido en inglés, visibiliza su doble linaje y anticipa la armónica convivencia de las diversas voces lingüísticas que, sin el menor atisbo de diglosia, se observa en la novela. A partir de esta construcción, la China encontrará una identidad dentro de otra percibiéndose mujer, hombre, india, inglesa, gaucha, todo a la vez, como una verdadera "alma doble" (2008, p. 148) o múltiple, una verdadera/o “...querido muchacho inglés" (2018, p. 151), nada en la China Iron parecerá fácilmente etiquetable a categorías rígidas, “... todo era otra piel sobre piel" (2018, p. 25).

Asimismo, debemos mencionar que la construcción de identidades subalternas conlleva, desde el discurso dominante, la percepción de que el "Otro" no forma parte de nuestra comunidad, no es un "Nosotros". Y "...no hay nosotros si no hay otros" (2018, p. 119) pone Cabezón Cámara en boca de un Hernández, devenido en personaje, para acentuar la pertenencia de este al proyecto de construcción de nación representativo de los grupos dominantes en el siglo XIX y gran parte del XX. Esta reescritura del Martín Fierro realiza un doble juego. Por un lado, coloca en un mismo plano autor y personaje. Hernández es un viejo coronel que le roba y tergiversa los versos a Fierro: “Pero Hernández es ladrón/Me empezó a afanar los versos/ Hizo libro'e mi canción" (Cabezón Cámara, 2018, p. 161). Por el otro, parodia y pone en práctica un proyecto de educación del gaucho que José Hernández había plasmado en Instrucción del estanciero de 1881, un libro que en la introducción lo describe como de "trabajo, de la faena ruda, de la constancia y el duro aprendizaje" (Hernández 1884, p. II). Es el fiel reflejo de la nueva alianza socio/industrial que mentara la Generación del 80: "asimilar al gaucho al sistema productivo como peón u obrero, exterminar al indio" (Rotker 1999, p. 210). La China y su séquito siente el hastío del lugar, "era como respirar agua, se sentían los borbotones apretando la garganta. No entraba bien ese aire: no salía. Habrían de ser el Campo Malo" (Cabezón Cámara, 2018, p. 139).

De esta manera, la granja fortín que dirige el coronel Hernández es presentada como la alegoría del campo civilizado, el recóndito borde, el último bastión antes del país de la "barbarie" y, como toda frontera, es el lugar de los límites: "y los límites auténticos nunca son neutrales sino antagónicos y presuponen exclusiones" (Rotker, 1999, p. 212). A los recién llegados los hacía "cavarse su propia fosa, su frontera, su antes y después" (Cabezón Cámara, 2018, p. 105). A partir de ahí, comenzaba su nueva vida. Un ritual de iniciación que dejaba claramente marcado en la tierra el paso de la barbarie a la civilización.

Es así que las ficciones orientadoras de las naciones, entre las que podemos inscribir al Martín Fierro, "suelen ser necesarias para darles a los individuos un sentimiento de nación, comunidad, identidad colectiva y un destino nacional" (Shumway, 
1993, p. 13). A partir de las operaciones de la Generación del Centenario el poema de Hernández pasa a ser "utilizado" por la elite gobernante para su propio relato identitario, que también se encuadraba dentro del nacionalismo cultural.

\section{2. "Y EN EL MISMO LODO / TODOS MANOSEAOS"2}

En Martín Fierro los hombres (Cruz y Fierro) reemplazan la vida familiar por la amistad incondicional con otro hombre "al que consideran el universo monolítico de sus afectos" (Melo 2011, p. 134). Esta relación, que se presenta como un peligro para la "sexualidad sana", encontraría un espacio entre las clases subalternas como señala Peralta (2013). Inconscientemente, José Hernández, así como Eduardo Gutiérrez en Juan Moreira, dio cuenta "que el dispositivo de sexualidad no está dirigido a los sectores populares y mucho menos, por supuesto, a aquellos sectores que no iban a ser incluidos en el proyecto nacional" (Melo 2011, p. 135).

Geirola, por su parte, afirma que la utopía de amor masculino "solo podía realizarse y sostenerse en el espacio de la barbarie, ya que en la civilización el amor entre hombres requería formas de machismo y reto" (1996, p. 327). En la tierra del indio "ni la ropa ni la forma de vivir está determinada por el sexo" (Cabezón Cámara, 2018, p. 157). Allí, en el país de los indios que narra la novela de Cabezón Cámara, Fierro aparece con trenzas y travestido cantando su amor carnal a Cruz:

No te voy a explicar yo

La delicia de tenerlo

Entero adentro de mí:

Su poronga un paraíso

Que me lo hizo ver a Dios

$Y$ agradecerle el favor.

Por haberme hecho nacer

Para sentir el placer

De ser amado endeveras

Y de endeveras clavado:

Ay, Jesús, qué maravilla.

¡Es zonzo el cristiano macho! (Cabezón Cámara, 2018, p. 163).

Cruz es el "doble" de Martín Fierro, su sombra y su reverso. El enigma mismo reside en el nombre, dirá Ezequiel Martínez Estrada (1948), porque es el ideograma anónimo. "Con ese signo firman los analfabetos. Además es, dentro de la simbología religiosa, la afrenta y el cadalso. Es también el revés de la Cara, en la moneda, y una de las suertes cuando se tira al azar" (1948, p. 76). Asimismo, Cruz es el que cruza la frontera con Fierro y de Fierro, se desglosa de él, por decirlo así, durante la pelea con la partida policial. Cruz cruza las fronteras de la ley para Fierro y la del indio con Fierro. Pero también, termina de explicitar, en la reescritura, el desbarajuste de las fronteras del género que algunos ven insinuado en el poema de Hernández.

La pertenencia de los sujetos a un sector étnico, social, de género rearticula la dinámica entre el "yo" y el "otro". Es así que, en esta relación binaria, la noción de 
otredad requiere un complementario necesario que se configura con la noción de identidad. Por lo tanto, la idea de alteridad permite revisar la representación de estos sujetos. De esta manera, alteridad e identidad serían "dos caras de una moneda determinadas por las operaciones de construcción social y personal que las definen." (Feuillet/Marengo 2017, p. 6). Sin embargo, la alteridad no siempre se relaciona con algo negativo. Aun así, la construcción de un "otro" favorece siempre la gestación de fronteras, líneas divisorias y diferenciaciones socio/culturales. Las aventuras... también suprime las fronteras entre un "ellos" y un "nosotros", entre un "yo" y un "otro/a":

(...) se fueron derritiendo los unos en los otros, como velas que arden juntas, hasta que se hizo difícil distinguir quién hacía qué con quién, eran una masa agitándose, enchastrada en su propio caldo de guascazos y charcos de china y muy pronto vómitos abundantes, terminaron desmayados más o menos para cuando salió el sol como flotando en una laguna con la compañía de los pedazos de vaca y las naranjas que se habían comido antes. (Cabezón Cámara, 2018, p. 127)

Esta cita muestra cómo el mundo del indio, que fue el purgatorio habitado por salvajes para el héroe hernandiano, es la utopía de igualdad para la China y su grupo. A sus ojos, personas y cosas se funden en un todo, en una equidad idealizadora que, por supuesto, omite la idea de cualquier tipo de frontera.

Todo esto envuelve una estrategia que va más allá de la esperada identificación cultural con el Martín Fierro. Aquí, la protagonista de la novela pasa "de china a lady y de lady a young gentleman" (Cabezón Cámara, 2018, p. 99) para demostrar que identidades de raza, de género y de clase, así como las diferencias lingüísticas, pueden ser desmontadas y reconstruidas en un discurso antiguo.

\section{CONCLUSIÓN: DE REESCRITURAS Y FRONTERAS}

La novela de Cabezón Cámara leída como una reescritura implicaría, como señala Florencia Garramuño (1997) para otras obras de la literatura de Brasil, Argentina y Uruguay especialmente, una vuelta al pasado no como un mero acto de cita estética, sino como un retorno a un momento de la tradición nacional que funciona como espacio de legitimación cultural.

Presenciamos en Las aventuras..., entonces, la construcción de un universo narrativo en el que se desarman aquellas fronteras socioculturales tan rígidamente edificadas por la literatura argentina decimonónica. De esta forma, también podemos suscribir esta reescritura a lo que Josefina Ludmer (2006) llama "nuevas escrituras" y que se caracterizan, entre otras particularidades, por borrar fronteras, borrar las divisiones entre géneros literarios, entre literatura urbana y rural, fantástica y realista, nacional y cosmopolita, "literatura pura" y "literatura social", y hasta borrar la separación entre realidad y ficción.

Visto así, parecería que el desapego de cualquier etiqueta termina por beneficiar la construcción de un territorio idílico. De este modo, la frontera, que blindara el mundo distópico del indio del de los cristianos en el texto de Hernández, auspicia de puerta a la utopía en la reescritura de Cabezón Cámara que culmina por encontrar en el pasado una mirada que indaga ya no en un arquetipo sino, más bien, en un antagonista que permite reformular el presente. 


\section{REFERENCIAS BIBLIOGRÁFICAS}

1.Aguilar, H. (2004). La performatividad o la técnica de construcción de la subjetividad. Recuperado de https://www.unrc.edu.ar/publicar/borradores/Vol7/pdf/La\%20 performatividad\%200\%20la\%20tecnica\%20de\%20la\%20construccion\%20de\%20la\%20 subjetividad.pdf

2. Universidad Nacional de Río Cuarto.

3. Cabezón Cámara, G. (2018). Las aventuras de la China Iron. Buenos Aires: Penguin Random House.

4. Feuillet, L. y Marengo, M. (2017). "Identidad y alteridad en la Literatura Argentina del Siglo XX y contemporánea". Recial. Dossier: Identidad y alteridad en la Literatura Argentina del Siglo XX y contemporánea, 8, 11. pp. 6-9.

5. Garramuño, F. (1997). I. Reescrituras. En Genealogías culturales. Argentina, Brasil y Uruguay en la novela contemporánea (1981-1991). pp. 11-24. Rosario: Beatriz Viterbo.

6. Geirola, G. (1996). José Hernandez. En Foster, D (ed) Latin Amercan Writers on Gay and lesbian Themes: Bio-Critical Sourcebook (pp.185-188). Westport: Greenwood.

7. Guerra, R. (1869). Lucía Miranda. Buenos Aires: Imprenta Americana.

8. Hernández, José (1884). Instrucción del estanciero. Buenos Aires: Casavalle Editor.

9. Hernández, J. (1978). El gaucho Martín Fierro y La vuelta de Martín Fierro. Buenos Aires: Editorial Ciordia.

10. Ludmer, J. (2006). Algunas'nuevas escrituras' borran fronteras. En Haydu, S. (2006)“Entrevista” en La Biblioteca. La crítica literaria en Argentina. pp. 26-31. Recuperado de https://www. bn.gov.ar/micrositios/admin assets/issues/files/f8fc71c90f75df20cf5d25e5e0ada398. pdf

11. Manso, S. (1916). La mujer de Martín Fierro. Buenos Aires: Casa Editorial Sabourin e hijo.

12. Marre, D. (2003). Mujeres Argentinas: las chinas. Barcelona: Universidad de Barcelona.

13. Martínez Estrada, E. (1948). Muerte y transfiguración de Martín Fierro. México D.F: Fondo de Cultura Económica.

14. Moyano, M. (2008). Literatura, Estado y Nación en el siglo XIX argentino: el poder instituyente del discurso y la configuración de los mitos fundacionales de la identidad. Amérique Latine Histoire et Mémoire. Les Cahiers ALHIM [En línea]. Recuperado de: http://journals. openedition.org/alhim/2892

15. Melo, A. (2011). Historia de la literatura gay en la Argentina. Representación social de la homosexualidad masculina en la ficción literaria. Buenos Aires: Lea.

16. Peralta, J. (2013). Espacios Homoeróticos en la Literatura Argentina (1914-1964). Barcelona: UAB.

17. Rotker, S. (1999). Cautivas. Olvidos y memoria en la Argentina. Buenos Aires: Ariel.

18. Shumway, N. (1993). La invención de la Argentina. Buenos Aires: Emecé.

19. Viola, L. (2017). "Aquí me pongo a contar". En Página 12, viernes 27 de octubre de 2017. 